\title{
Web-disclosure practices for transparency and the sustainability of non-profit organisations
}

\author{
Ramesh Nair $^{1}$ (D) Roshayani Arshad $^{1}$ (D) $\cdot$ Ruhaini Muda $^{1}$ (D) \\ Siti Aeisha Joharry²
}

Received: 6 July 2021 / Accepted: 28 December 2021 / Published online: 6 January 2022

(c) The Author(s), under exclusive licence to Springer-Verlag GmbH Germany, part of Springer Nature 2022

\begin{abstract}
In times of economic uncertainty, non-profit organisations (NPOs) are struggling to stay afloat as funds diminish and partners prioritise their own survival. This study is anchored to the premise that the sustainability of NPOs is highly dependent on their ability to gain stakeholder trust, and that strategic communication is central to achieving this. We focused on the practices of Malaysian NPOs in measuring and reporting the impact of their programmes. Through an analysis of their official websites, we sought evidence of how programme outcomes were reported and the extent to which NPOs engaged in dialogic communication using readily available multimedia tools. Finally, we devised and tested a programme evaluation instrument for use by Malaysian NPOs when planning for outcome-driven activities. The findings revealed that a significant number of Malaysian NPOs were operating without an official website. Those which had websites generally appeared to provide opportunities for dialogic communication with stakeholders and the wider community. A survey of NPOs suggested that they took dialogic communication seriously and responded to communication in a timely manner. However, the NPOs were less successful in reporting their initiatives in a way that would help them gain stakeholder trust. As such, opportunities to convince potential funders for future activities appear limited, threatening the sustainability of the NPOs. The second phase of the study suggests that the use of the programme evaluation instrument helps in sensitising NPOs about planning for and reporting impactful programmes.
\end{abstract}

Keywords Trust $\cdot$ Sustainability $\cdot$ Web-disclosure practices $\cdot$ Outcome report

Ramesh Nair

ramesh@uitm.edu.my

1 Accounting Research Institute, Universiti Teknologi MARA, 40450 Shah Alam, Malaysia

2 Academy of Language Studies, Universiti Teknologi MARA, 40450 Shah Alam, Malaysia 


\section{Introduction}

Non-profitNonprofit Organisations (NPOs) play a significant role in supporting government-led social impact initiatives; however, the partnership is complex and researchers such as Cook et al. (2017) have even argued that under some conditions, NPOs can negatively affect the responsiveness of government agencies. The success of any organisation, even NPOs, lies in their ability to practice good governance. Indeed, good governance practices serve to ensure the sustainability of NPOs.

NPOs increasingly see themselves as being part of the community development process rather than as charity organisations, and this encourages them to subscribe to a participatory community development model where empowerment of the target community is to be achieved through a clear understanding of issues, leadership, and impact assessment (DoanBao et al., 2019). The success of any NPO-driven initiative hinges on access to finances provided by external entities which include government agencies and profit-driven private corporations. However, accessing funds is a complex process which requires both NPOs and funding organisations to mull over various factors such as reputational risk when they join forces as part of social alliances (Bocquet et al., 2020). Among others, funding partners, be they organisations or individual donors, rightfully demand that NPOs provide information which would allow them to assess the capacity for effective delivery of the social initiatives they are supporting. This is highlighted in a study by Kolhede and Gomez-Arias (2021) who found that regardless of the segment to which they belonged, donors were all highly dependent on information such as organisational mission and efficiency.

Furthermore, as part of social alliances, NPOs and funding agencies need to agree upon the outcomes and projected long-term impact of planned initiatives. This needs to be followed by action on the part of NPOs who need to design a focused impact assessment framework, put into place a plan for action, initiate the project, and then finally report outcome. Ricciuti and Calo (2018) observe that interest in the assessment of social impact by NPOs has been gaining momentum; however, in their study of Italian foundations which had the financial means of executing social impact assessments, social impact reporting was "rare, usually unstructured, and very poorly communicated" (p.570). Despite increasing pressure to measure and report performance, NPOs are still failing because they lack the capacity and capability (Bach-Mortensen \& Montgomery, 2018). This challenge frames the focus of the present study as we examine existing assessment and reporting practices of Malaysian NPOs for the activities which they carry out. In addition, we also test a framework for use by NPOs to assess and report outcomes, thereby gaining stakeholder trust and ensuring their sustainability. 


\section{Theoretical background}

Web disclosure involves the voluntary dissemination of information to the public, and this includes performance disclosures which provide stakeholders with an understanding of how an NPO is performing in terms of meeting their goals and impacting their target beneficiaries (Lee \& Blouin, 2019). This voluntary sharing of information is best understood within the scope of stakeholder theory and legitimacy theory.

Stakeholder theory serves to explain the need for voluntary web disclosure as it centre-stages the stakeholders who are important to any organisation. In an extensive discussion on stakeholder theory and its real world application, Freeman et al. (2020) contend that the theory is rooted in observations of value creation within organisations, with the premise that maintaining strong stakeholder relations, through having shared values and establishing trust, is key to this value creation. The theory further posits that organisations are reliant on the approval and support of their stakeholders, and the challenge for any organisation is to meet varying stakeholder interests while directing those interests towards a shared goal. In the case of NPOs, the effort made to meet stakeholder demands is dependent on the influence of those stakeholders in meeting operational needs. The greater the influence of a stakeholder, the more important it becomes for an NPO to reveal how their activity outputs and outcome meet the expectations of that stakeholder. In turn, this disclosure of information helps stakeholders determine value creation for themselves. For the NPO, disclosing information helps establish trust, and ensure that there is continuous access to resources which are controlled by the stakeholders (Bosetti, 2018). Therefore, web disclosure makes for an affordable and efficient option for NPOs to share information and manage the demands of stakeholders.

Beyond meeting stakeholder needs, disclosing information about performance via web disclosure practices also serve to legitimise the existence of NPOs, and this is supported by legitimacy theory. According to Burlea and Popa (2013), legitimacy theory forwards the view that organisations disclose information about their various activities as a way of legitimising their operations and gaining social acceptance. Organisations which fail to do this risk losing access to resources which are afforded to them by society. Hence it follows that information disclosure by NPOs serve a dual purpose. It legitimises the existence of NPOs in the eyes of the public at large, and it offers stakeholders access to information to ascertain a match to their interests or even determine potential risks (Burlea \& Popa, 2013). However, in drawing on legitimacy theory, Deegan (2019) cautions that it would be too simplistic to conclude that all disclosure serves to strategically legitimise the presence of organisations. He asserts that information disclosure is also governed by "various cultural and normative reasons" (p.2319), and so it is possible that some information is not disclosed even though the legitimacy of an organisation comes into question.

The disclosure of information is evidently a common thread that runs through both legitimacy theory and stakeholder theory. For this reason, both theories provide the framework for examining the reporting practices of NPOs. 


\section{Reporting outcomes and impact through web disclosure practices}

The present study is located at the intersection of two broad areas of research, namely outcome and impact assessment, and web disclosure practices for greater transparency. Both research domains have received a great deal of scholarly interest. In more recent times, outcome and impact assessment and reporting have been examined through the lens of not-for-profit organisations (Connolly et al., 2013; Hyndman \& McConville, 2018; Polonsky, Grau \& McDonald, 2016; Yang \& Northcott, 2018).

The interest in NPOs (read as synonymous to charities, not-for-profit organisations, foundations, social or third sector organisations) has been largely motivated by the contention that their ability to communicate the value of their funded work determines their capacity to sustain their initiatives (Polonsky et al., 2016). However, research findings reveal that NPOs struggle to provide quality evidence of the outcome and long-term impact of their activities because of a failure to determine outcome indicators and develop an evaluation system, as well as a lack of motivation to be accountable to their stakeholders (Bach-Mortensen \& Montgomery, 2018).

Despite evidence of enhanced public confidence resulting from voluntary web disclosure practices, NPOs have failed to practice this even when regulatory agencies have been calling for the public disclosure of information (Blouin, Lee \& Erickson, 2018). In an examination of websites belonging to community foundations in the UK and Italy, Rossi et al., (2020) found that information sharing was capricious, with few sharing information such as organisation priorities and longterm goals. Cordery et al. (2019) opine that poor reporting practices are also the result of NPOs being guided by varying local requirements rather than a globally accepted set of standards. While they make this call in the context of financial reporting practices, the need to extend this to the non-financial reporting of performance are made by others such as Boateng et al. (2016), and Yang and Northcott (2019). This type of quality reporting is however difficult for most NPOs which are challenged by limited financial resources, a lack of technical expertise, and a lack of access to the right instruments to measure and report performance (Bach-Mortensen \& Montgomery, 2018). Providing NPOs with support for measuring and reporting outcomes is therefore necessary to help them establish stakeholder trust, better sustain their operations, and impact target communities.

The reporting of activity outcomes is an important aspect of effective communication with stakeholders, and NPOs depend a great deal on their websites for this. Lee and Blouin (2019) assert that the web disclosure practices of NPOs serve a variety of goals including enhancing public confidence and increasing donations. However, in an earlier study by Blouin et al. (2018), it was concluded that despite a strong correlation between voluntary web disclosure and donations received, many NPOs have failed to adopt proper disclosure practices. More recently, Carvalho et al. (2020) reported that the demand for information by stakeholders sees NPOs offering both financial and non-financial disclosures through their websites; however, the degree to which this information is disclosed 
is dependent on various factors such as the size, age and certification of financial reports. Unfortunately, there has been relatively little research focus on the web disclosure practices of Malaysian NPOs. To date, only one study by Shah et al. (2016) has focused on web disclosure practices of Malaysian NPOs. In that study, the researchers compared the web disclosure practices of NPOs in Malaysia and Singapore and reported of a correlation between the size and financial performance and the amount of web-disclosed information. However, the research paper offered little insights into how levels of disclosure were determined except for stating that the analysis drew on a modified version of the nonprofit virtual accountability index. The present study addresses the dearth in literature on web disclosure practices by NPOs by examining the websites of Malaysian NPOs. Furthermore, given the gap in literature about the capacity of NPOs to measure and report outcomes of their activities through web disclosure, we examine the reporting practices of Malaysian NPOs and test the use of a programme evaluation instrument to support NPOs with planning for and reporting on outcomebased initiatives.

The present study is also informed by the contention that although websites provide NPOs with an excellent platform for enhancing stakeholder confidence and establishing trust among existing and future collaborators, many NPOs have failed to adopt proper web disclosure practices (Lee \& Blouin, 2019). This represents lost opportunities because effective web disclosure practices can serve to legitimise the work of NPOs and reinforce their commitment to transparency. It so follows that the specific research questions of the present study are:

a. What communication strategies do NPOs employ when reporting their initiatives to stakeholders?

b. How successful are NPOs in measuring and reporting the outputs and outcomes of their programmes?

c. How can a programme evaluation instrument devised for the present study support NPOs in measuring, assessing and reporting programme outputs and outcomes?

By answering the research questions above, we intend to understand the extent to which Malaysian NPOs leverage on web disclosure opportunities to legitimise their role in society and meet stakeholder needs. Towards these same ends, we also seek to determine how NPOs can be supported in assessing outputs and outcome, and reporting their performance through their websites.

\section{Method}

The 6-month study involved several phases which were guided by the research objectives. For addressing the first two objectives, the researchers had to identify the NPOs which would make up the corpus for analysis. A review of previous studies revealed that the sample of NPOs which were selected to examine web disclosure practices was based on ratings by regulatory agencies (Gandia, 2011), listing 
by independent bodies such as Guidestar, a US-based website which lists American NPOs (Lee \& Joseph, 2013) or listings by an umbrella body such as an association of NPOs (Carvalho et al., 2020). Unfortunately, drawing on a similar database was not possible in the Malaysian context as there has been no initiative to independently list or rank Malaysian NPOs, nor is there an umbrella body offering membership to all NPOs in Malaysia. The only sources would be databases made available by regulatory agencies which register NPOs, namely, the Registrar of Societies Malaysia (ROS) and the Companies Commission of Malaysia (CCM). A visit to the ROS website revealed that a full list of NPOs was not made available. Instead, visitors to its site needed to type in the names of individual NPOs in a search engine to locate details about them. In contrast, the CCM website listed NPOs which register under two categories, namely, Companies Limited by Guarantee and labelled as "Berhad" (809 organisations, updated 24 January 2021), and Companies Limited by Guarantee but not labelled as "Berhad" (1334 organisations, updated 24 January 2021). Given this limited access and an absence of any independent listing or ranking of Malaysian NPOs, the list of 2143 NPOs made available in the CCM website served as the corpus for the present study.

An Internet search was carried out in December 2020 to determine the number of NPOs which maintained websites for disseminating information. At the same time, an instrument was designed and refined to capture data on the outcome reporting practices of NPOs as well as evidence of their dialogic communication practices. For this, 13 NPO websites were randomly selected for testing and refining the instrument. The refined version of the data collection instrument was made up of several sections to facilitate the content analysis (Table 1):

Once refined, the instrument was used to collect information through a content analysis of 100 NPO websites.

Table 1 Evidence of dialogic communication opportunities and reporting practices

\begin{tabular}{ll}
\hline Section & Subsection \\
\hline Dialogic communication opportunities & General contact number \\
& Direct contact number \\
& Social media links \\
& Feedback form \\
& e-mail address \\
Reports of past activities & Annual report \\
& Newsletter \\
& Press release \\
& Events/Activities list \\
Content of last report & Outcome/Impact report \\
& Input \\
& Description of activities \\
& Output \\
& Outcomes \\
& Impact \\
\hline
\end{tabular}


Unlike previous studies in other parts of the world which selected NPOs based on published ranking systems, the selection of the NPOs for the present study was random and anchored to 2 lists of NPOs (NPOs labelled as "Berhad" and those not labelled as "Berhad") presented on the website of CCM. NPOs which did not have a website as of 24 January 2021, were removed from the list. It was determined that 100 NPO websites would serve as the sample for investigation. All NPOs with websites were listed in alphabetical order, and every 6th NPO in the list was selected to make up the sample of 100 NPOs for analysis.

Next, 536 NPOs registered with CCM and which possessed their own websites were invited to participate in a survey to understand their dialogic communication and reporting practices. A total of 52 NPOs participated in the survey. In addition, online face-to-face interviews were conducted with two NPOs to further understand the rationale and justifications for NPO reporting and dialogic communication practices.

To address the final objective of the study, we put out a call to NPOs through our personal contacts inviting participation in the study. We formalised a partnership with the first NPO to respond, an English language teaching association (henceforth referred to as ELTNPO). The ELTNPO was invited to test the use of a programme evaluation instrument. The ELTNPO was provided with a monetary incentive to participate in the study. The incentive was used by the NPO to carry out an activity and test the use of the instrument. The design of the instrument was guided by the impact assessment logic model (Robert, 2013) as reflected in the Fig. 1 below:

The researchers worked with members of the ELTNPO on the task of managing an activity and preparing the outcome report. Feedback was collected from the organisers on their experience with using the instrument and preparing the outcome report.

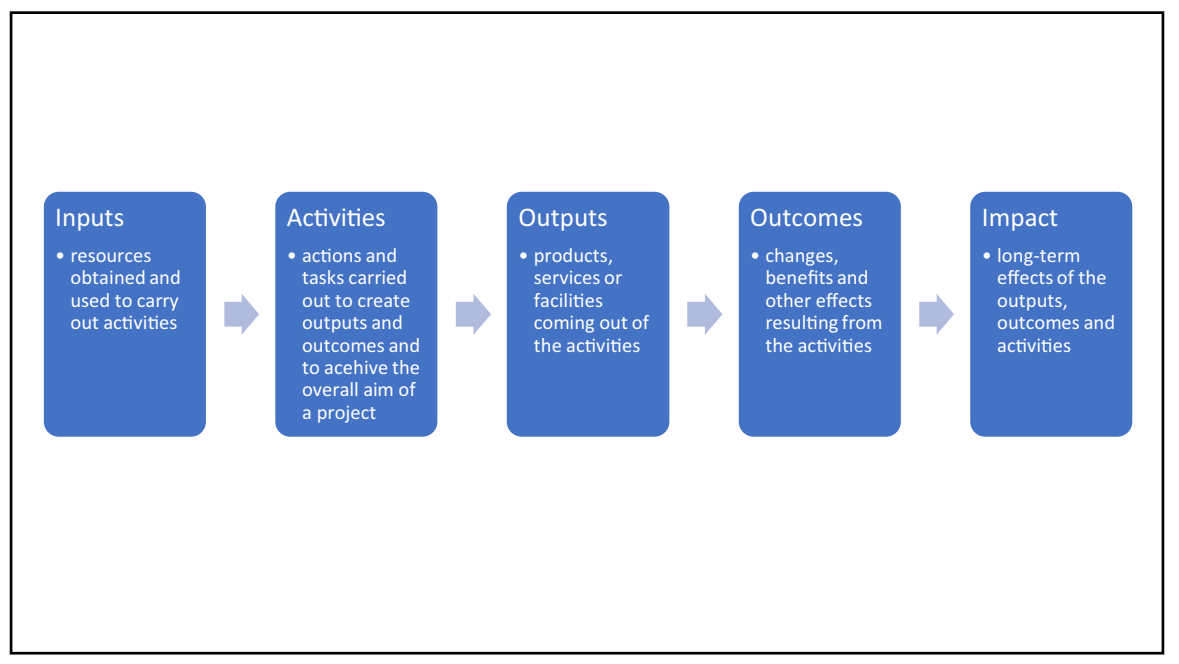

Fig. 1 Impact Assessment Logic Model (Source: Robert, 2013) 
The contention which guided the present study was that NPOs which voluntarily disclose information through their websites are likely to be in a better position for establishing stakeholder trust and drawing public support for their endeavours. The second phase of the study was therefore geared at understanding how NPOs could better leverage on the many activities they carry out by measuring the outcomes of the activities and reporting it to stakeholders and the public at large through their websites.

We undertook to develop an online programme evaluation instrument for use by NPOs. The development of the instrument was guided by existing literature on impact assessment and transparent reporting practices (Robert, 2013; Bouten et al., 2011). The ELTNPO was invited to use the online instrument and offer feedback on various aspects including clarity of instructions and ease of navigation. At the same time, two independent experts with a research background in web disclosure practices were invited to review the instrument. Based on all feedback, the final version of the instrument was created to include items presented in Table 2.

The items in Table 2 were presented as a series of questions with response options. Once all the right information is completed by users, the online form is designed to generate a flowchart, similar to the format of the impact assessment logic model, to guide data collection and the writing of an outcome report. The instrument is therefore geared at creating awareness about the importance of planning for and collecting evidence of outcomes from activities carried out by NPOs.

Once the system was refined, the ELTNPO was invited to use it for the planned activity. Through a series of discussions, it was decided that the ELTNPO would organise a competition for English language teachers to present successes they had had with teaching and learning during school closures forced by the COVID19 pandemic in Malaysia.

Table 2 Items in Programme Evaluation Instrument

\begin{tabular}{ll}
\hline Sections & Specific Information to be completed \\
\hline Organisation details & Name of organisation \\
& Name of proposed programme \\
& The main goal of the programme \\
& The organisation objective which \\
matches the goal of the programme & Target beneficiaries \\
& Success criteria \\
Activity details & Measurements of the success criteria \\
& Input - resources used for the project \\
& List of activities \\
& Target outputs \\
& Target outcomes \\
& Projected long-term impact \\
Data collection instruments
\end{tabular}




\section{Results}

The findings are presented in three main sections. We first report on the communication strategies used by the NPOs in their web disclosure practices. Next, we narrow our focus to the reporting practices of the NPOs to understand the effectiveness of their measuring and reporting of outcomes and impact. Finally, we report on the use of a programme evaluation instrument by an NPO for carrying out an activity and reporting its outcomes.

\subsection{NPOs web disclosure practices}

A search of NPOs registered with the Companies Commission of Malaysia revealed that a total of 2143 NPOs were listed as of 24 January 2021. Next, the researchers undertook a search to locate the websites of all 2143 NPOs. It was found that only 663 of these NPOs maintained their own website. Of this number, 197 were NPOs labelled as "Berhad" and 466 were NPOs without this label.

It should be noted that every NPO which registers with CCM will be listed as a "Company Limited By Guarantee" (CLBG). The CLBG category is meant for organisations which identify themselves as a public company without share capital for nonprofit purposes. Unlike NPOs with register with ROS, a CLBG must show evidence of possessing funds of MYR1 million. Companies which register in this category, begin with the "Berhad" label attached to their name. However, once registered, an NPO can submit an application to have the label removed. Any organisation intending to use the term "Yayasan" (meaning "Foundation") must apply to have "Berhad" omitted, while other organisations registered as CLBG can apply for the removal of "Berhad" after being incorporated for 3 years (JTC Kensington, n.d.). While it is evident that NPOs registered under CCM are financially stable, it was found that only $30.9 \%$ of these NPOs have set up websites to disclose information and engage with stakeholders. The number of Malaysian NPOs which fail to maintain an official website is high when compared to observations in other studies such as that by Carvalho, Ferreira and Lima (2020) who reported that $26 \%$ of Portuguese charities in their sample did not maintain an institutional website.

Of the 663 NPOs which maintained websites, the researchers undertook a content analysis of 100 randomly selected NPOs (every 6th NPO selected from a list of 663 which were listed alphabetically). As they were random selections, their backgrounds varied significantly and this allowed the researchers to examine a widespectrum of NPOs. The oldest NPO from the list of 100 was established in 1837 (Malaysian International Chamber of Commerce and Industry) while the youngest NPO was formed in 2018 (Yayasan Hartalega). The websites of 11 NPOs which made up part of the corpus did not disclose information about when they were established.

Communication strategies can be discussed in very broad terms as communication affects so many aspects of human life. Strategies employed by organisations to communicate with stakeholders include providing access for stakeholder 
engagement, responding to stakeholders, and providing information which serves the interest of both the organisation and the public (Kent \& Taylor, 1998, cited in Wirtz \& Zimbres, 2018). In the present study, we narrowed our focus to strategic virtual communication practices as presented by Waters et al. (2009) in discussing the online communication practices of NPOs. They opine that virtual communication strategies must consider three main elements, namely disclosure, dissemination and involvement (Gálvez-Rodriguez et al., 2014). These strategies draw focus to the importance of moving beyond the one-directional form of communication which involves disclosure and dissemination to dialogic or two-way communication opportunities which emphasise involvement.

The websites were therefore examined for evidence of dialogic communication based on the contention that establishing trust necessitates the sharing of information and engaging in communication with stakeholders who visit the organisation's website and social media sites (Wirtz \& Zimbres, 2018). Drawing on the instrument used for analysing dialogic communication in Nair et al. (2020), we examined all 100 NPO websites for opportunities presented for two-way communication Fig. 2.

The findings reveal that a significant majority of the NPOs $(96 \%)$ provided a general number to receive telephone calls. However, very few $(6 \%)$ provided a name of a person to direct calls to. Surprisingly, not all NPOs provided links to their social media sites, suggesting that the desire to connect with the public at large through immediate conversations may not be strong. It appears that communication through social media sites is not necessarily the most preferred option despite the opportunities for more immediate, real-time engagement. This observation contests the claims of past studies which suggest a preference for the sharing of experiences via social media sites (Ramos et al., 2019). A search was also carried out to determine if feedback forms were provided in the NPO websites as they too reflect a desire to

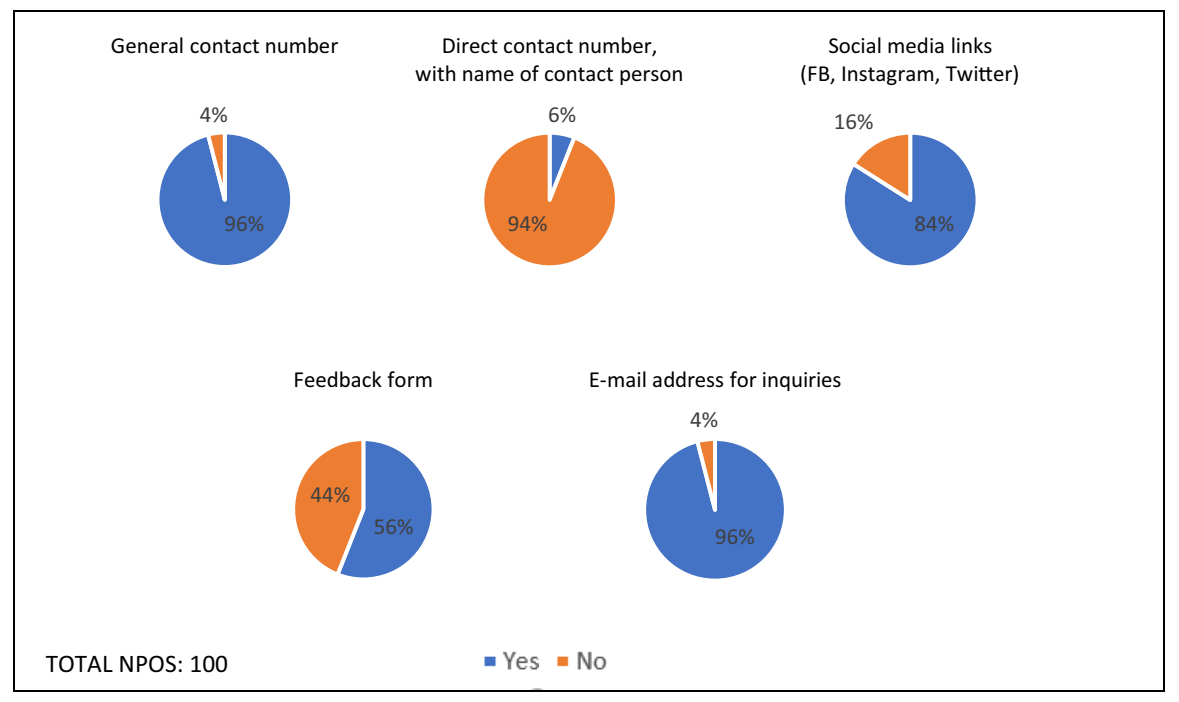

Fig. 2 Dialogic Communication Opportunities 
engage with stakeholders (Midin et al., 2017). However only 56\% of the 100 websites offered feedback forms to its visitors. Finally, it was found that all but three websites (96\%) listed email addresses for direct communication. In fact, some NPOs were found to offer more than one email address, specifying alterative e-mail addresses for different purposes such as general inquiries, volunteering, and applying for positions.

To further understand the communication practices of Malaysian NPOs, a survey was also carried out. Through this survey, it was found that $50 \%$ of the NPOs did not follow a schedule for updating information on their websites. A total of $14.6 \%$ of NPOs reported updating their websites weekly while another $16.7 \%$ reported updating their sites on a monthly basis. The survey also revealed that not all NPOs offered the full range of dialogic communication opportunities to engage with their stakeholder. The survey showed that $79.2 \%$ of all respondents provided details of a mailing address on their website, $93.8 \%$ provided an email address for communication purposes, $81.3 \%$ provided a telephone contact number, $29.2 \%$ provided feedback forms, and $77.1 \%$ provided links to their social media sites via their website.

When asked about the most preferred mode of communication by stakeholders, $41.7 \%$ of the respondents identified e-mail communication as the most preferred mode, and this was followed by $20.8 \%$ who identified text-messaging services such as WhatsApp and only $18.8 \%$ who reported that stakeholders engaged with them most through social media sites. Communication via telephone calls trailed behind at just $10.4 \%$. The respondents were also asked about the mode of communication which they perceived as the most efficient way of communicating with their stakeholders and beneficiaries. Again, e-mail communication was perceived as the most efficient (26.5\%), and this was followed by an equal number of respondents who identified text-messaging services $(24.5 \%)$ and telephone communication $(24.5 \%)$. Interestingly, only $14.3 \%$ of the respondents perceived communication via social media sites as efficient. When responding to emails and letters, an equal number of respondents reported replying within the same day (44.9\%) or within 3 days $(40.8 \%)$. In contrast, $77.6 \%$ of respondents reported responding to messages via text-messaging services within the same day while $18.4 \%$ responded in 2 or 3 days. Responses within the same day was also high for messages posted on social media sites $(54.2 \%)$ while another $35.4 \%$ reported responding to social media postings in 2 or 3 days.

Telephone interviews were conducted with two NPOs to further understand their dialogic communication practices. One was a wildlife conservation NPO committed to the protection of Malayan sun bears while the other was an NPO supporting disadvantaged women from low-income communities. Prior to the interviews, the websites of both NPOs were examined to guide the conversation. In the interviews, both NPOs strongly agreed that they regarded their websites as vital platforms for engaging with their key stakeholders. The wildlife conservation NPO reported having spent years developing the site into what it had become. They were guided by the content of websites managed by reputable NPOs in the area of conservation. In contrast, the website managed by the other NPO was launched only recently after they migrated from an older site. In terms of engaging with their stakeholders and the public at large, both NPOs were very aware about the need to engage via their websites. The wildlife conservation NPO for example offers information on their 
website in both English and Mandarin because they had been receiving a great deal of support from Taiwan. They reported plans to translate their website into Japanese as the Japanese were also considered strong supporters of wildlife conservation initiatives. The NPO which supported disadvantaged women agreed that keeping the public informed and engaged was important for their sustainability; however, they admitted that updating the website was not done regularly because they did not have the manpower to do so.

\subsection{Measuring and reporting outcomes of programmes}

In order to propose a systematic way of measuring and reporting the outcome of NPO programmes, there is a need to first understand existing practices. A content analysis was therefore carried out for the 100 randomly selected NPOs to ascertain if they reported their activities via their websites, and the format in which the reports were presented. Of the 100 NPOs, 6 did not report past activities in any format. As revealed in fig. 3, the most popular mode used for reporting activities was via brief postings on their website events or activities link ( $86 \%$ of all NPOs). This was followed by $18 \%$ of all NPOs reporting past activities via published newsletters and $10 \%$ reporting their activities via their annual reports. A few NPOs (6\%) reported their past activities via press releases and none showed evidence of publishing stand-alone outcome reports.

Interviews with 2 NPOs revealed that there was indeed awareness about the importance of sharing information of activities through their web disclosure practices. The representatives of both NPOs asserted that they were committed to effective website reporting practices, with timely updates. However, they reported that updating their websites was time consuming, and they did not have the resources for this.

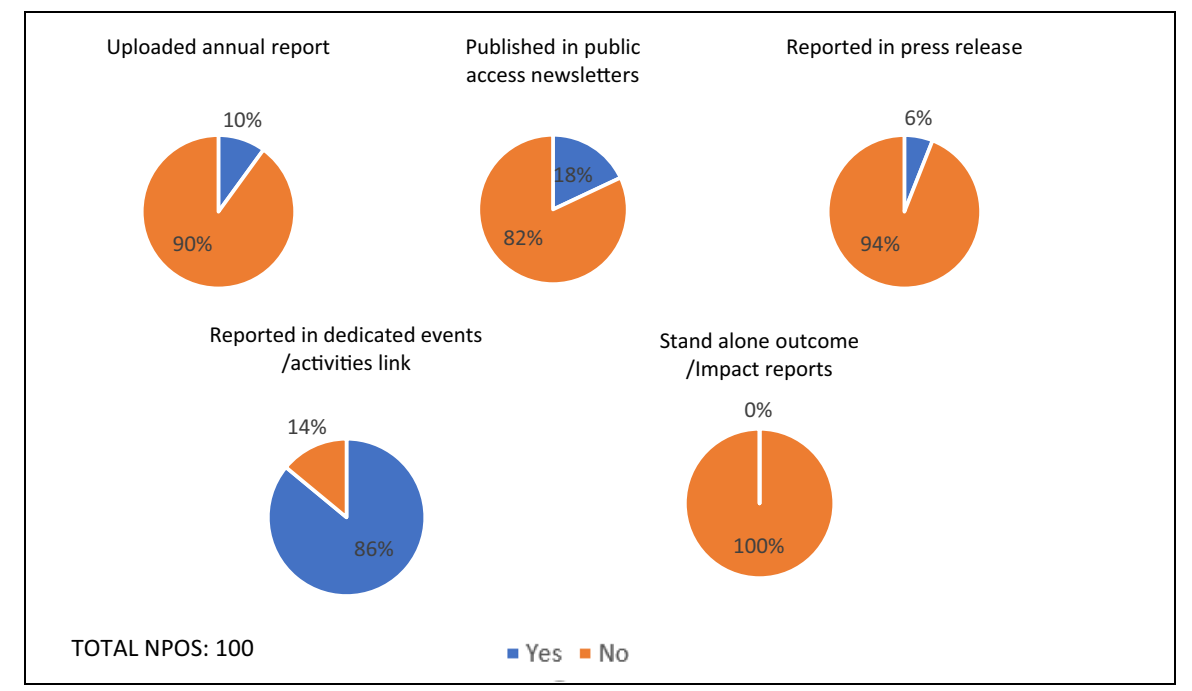

Fig. 3 Format for reporting past activities 
The interview sessions with the two NPOs also revealed that the key message which they intended to communicate via reports was how their values or cause was congruent with their key stakeholders. The importance of communicating values is confirmed in another study by Nageswarakurukkal et al. (2020) who found that $60 \%$ of potential donors described the mission of the NPO as the most important factor to consider when making a donation. Communication with potential donors was in fact stressed by both representatives of the NPOs we interviewed. One of the NPOs engaged a professional consultant for measuring its performance and reporting to funders while the other NPO reported designing performance-based measures guided by information required by funders.

The reports of past activities presented on the websites were also examined for recency. It was found that the regularity with which activity updates were provided varied, and this is reflected in the table 3 below:

Based on a review of the NPO websites up to 31 March 2021, it was found that $40 \%$ of the NPOs had updated information of past activities in the last 6 months. Of this, $21 \%$ of NPOs had updated information about their past activities within the last 3 months. However, it was also observed that almost a quarter of all NPOs (22\%) had not updated their websites with information of past activities in over a year while another $13 \%$ presented reports without clearly indicating the date of the report. The regular updating of information about past activities is important as it is a sign of commitment towards keeping stakeholders informed.

Beyond determining whether NPOs reported their activities, there was also a need to determine if the information reported was comprehensive. This is because the comprehensiveness of reports contributes to greater transparency and accountability (Bouten et al., 2011). Therefore, to determine comprehensiveness, the framework for impact assessment and reporting by the CASS Centre for Charity Effectiveness (Robert, 2013) was used to determine if the reports contained the elements of input, the work carried out, the outputs, outcomes and potential impact.

The most recent report presented on each of the NPO websites was analysed to determine if they reported input, a description of the work carried out, output, outcome and impact. The analysis of the reports revealed that the most recent

Table 3 Regular updates of activities on NPO websites

\begin{tabular}{lll}
\hline Last Updated & N & $\%$ \\
\hline Q1 2021 & 21 & 21 \\
Q4 2020 & 19 & 19 \\
Q3 2020 & 10 & 10 \\
Q2 2020 & 2 & 2 \\
Q1 2020 & 6 & 6 \\
2019 or earlier & 23 & 22 \\
No date indicated & 13 & 13 \\
Not applicable (No reports on & 6 & 7 \\
$\quad$ website) & & 100 \\
TOTAL & 100 & \\
\hline
\end{tabular}




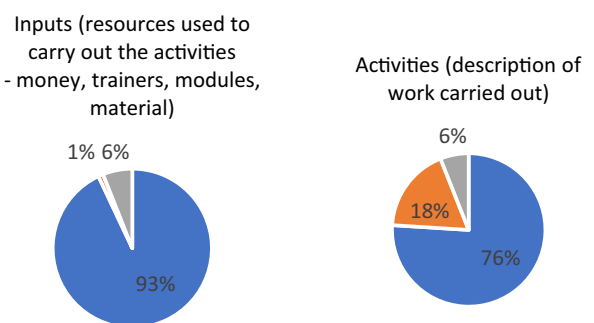

Outcomes (changes, benefits, learning that result from what the project provides, e.g increased income after implement changes, better student performance after teachers are trained)

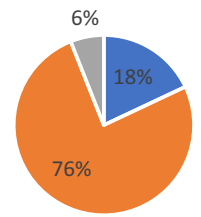

Outputs (products, services or facilities that result from a project's activities, e.g financial training, business proposals, trained teachers)

$6 \%$

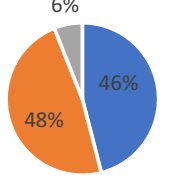

Impact (broader or longer-term effects of a project's outputs, outcomes and activities, e.g former participants report financial independence, students report confidence in communicating in English)

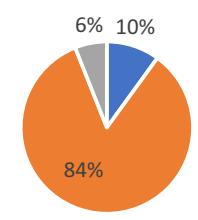

TOTAL NPOS: 100

Fig. 4 Content of past activity reports

reports, regardless of the mode used (annual report, newsletters, description in the events page, etc.), contained a few elements, but never all five.

As reflected in fig. 4, most reports $(93 \%)$ included the input that went into the organisation of the activities, while $76 \%$ of reports described the activities which made up the programmes. However, the majority of reports failed to report outputs, while a mere $18 \%$ made attempts at reporting outcomes and impact (10\%).

Of the 100 websites which were analysed, only one NPO attempted to provide stand-alone reports. Forever Sabah which describes itself as a civil society entity carries out projects and programmes geared at empowering communities in the state of Sabah. In their activity links, stand-alone reports of past activities were uploaded (see https://www.foreversabah.org/resources). However, none were impact or outcome reports based on the framework prescribed in the present study. Instead, the reports varied from full research reports (Smallholder Readiness for Roundtable on Sustainable Palm Oil (RSPO) Jurisdictional Certification of Palm Oil by 2025: Results from field studies in Sabah's Telupid, Tongod, Beluran \& Kinabatangan Districts) to project justification reports (Preventing Further Floods in the Moyog Catchment: Myths and Realities).

The variations observed in the reporting practices of the NPOs which made up the corpus of the present study reiterates past observations that disclosure practices vary depending on factors such as the size and age of NPOs (Carvalho et al., 2020). Comprehensive reporting of past activities, as defined by the CASS Centre for Charity Effectiveness (Robert, 2013) framework, should include the reporting of input, the activity carried out, the outputs, outcomes and potential impact. 
However, as fig. 4 shows the reports were generally not successful in reporting these five dimensions.

The survey questionnaire which was distributed to NPOs also attempted to elicit information on the activity reporting practices of the NPOs. According to the respondents, the most preferred way of informing their members or the public of upcoming activities was through their social media sites, and this was followed by the use of text-messaging services, sending emails and only then by posting information on their website.

Next, the respondents were asked if they reported the activities they carried out to their members and/or the public at large. As shown in fig. 5, almost half the respondents $(49 \%)$ made it a point to report every activity. The remaining reported informing their members and/or the public most of the time $(28.6 \%)$ or sometimes $(20.4 \%)$. Despite this, almost all respondents $(98 \%)$ either agreed or strongly agreed that reporting activities is important for NPOs.

Consistent with observations made in the content analysis of the NPO websites, the respondents reported that the most common means used to report past activities was by sharing a brief write-up via social media sites. This was followed by those who said they prepared brief independent reports, and those who reported activities via newsletters. The large majority of the respondents $(71.7 \%)$ claimed that they shared their activity reports within a week after the event ended while another $21.7 \%$ reported that this was done between one and four weeks after an event.

Next, the respondents were asked if they collected data through surveys when they run their activities. To this, only $27.1 \%$ reported doing so all the time. Another $39.6 \%$ reported doing so most of the time and $22.9 \%$ reported doing so sometimes. In instances when surveys are conducted, only $30.6 \%$ of all respondents reported using the data in their activity reports while an equal number $(28.6 \%)$ reported using the data most of the time or sometimes.

\section{Reporting activities to members and public at large}

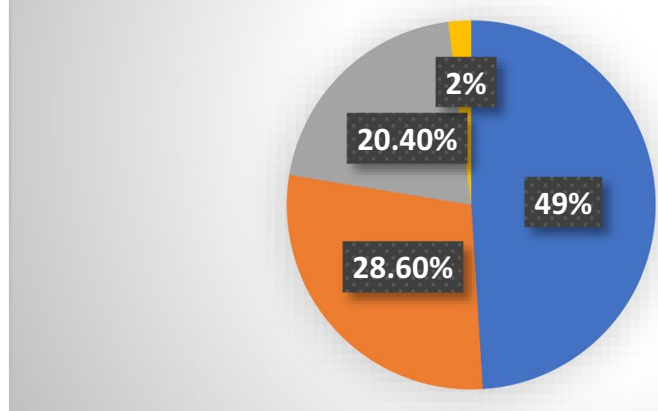

$$
\begin{aligned}
& \text { Always } \\
& \text { Most of time } \\
& \text { Sometimes } \\
& \text { Rarely } \\
& \text { Never }
\end{aligned}
$$

Fig. 5 Reporting activities to members and the public at large 


\subsection{Testing of programme evaluation instrument}

The first meeting with the ELTNPO involved a discussion on outcome reporting. The session revealed that the ELTNPO did not have experience in preparing outcome reports for their past activities. They agreed that information sharing was important and were confident that their activities had an impact on their participants. However, while they had some data from their past activities, including some evidence captured through feedback from the participants, there was no attempt to report the activities to stakeholders. In the same meeting, members of the ELTNPO were briefed about the principles of outcome reporting before deliverables were spelt out and deadlines set for the tasks the ELTNPO had to complete for the study.

After a week, a second meeting was held for the ELTNPO to present their proposed activity. At this meeting, they were introduced to the refined programme evaluation instrument. The ELTNPO used the instrument to guide them with their data collection plans. Upon completion of the event, the ELTNPO presented an outcome report of their programme, and an interview was held to get feedback on the use of the programme evaluation instrument.

According to the ELTNPO, the objective of the competition was to follow up on two earlier webinars which they had carried out, and have English language teachers use the knowledge gained from those webinars to showcase innovative classroom practices. The specific objectives of the competition were to recognise English language teachers' efforts in supporting student learning during the school closures, and to showcase best practices in remote learning that had positively impacted student engagement in English language learning. These objectives were aligned the broader association objectives of promoting the teaching and learning of English in Malaysia, and contributing towards to improved standards in English language education in Malaysia.

Upon completing the planned activity and submitting the outcome report, the ELTNPO was invited to an interview session aimed at understanding their experience of organising and reporting the outcomes of an activity using the programme evaluation instrument. Two members who were directly involved in organising the activity participated in the interview session. They felt that the first briefing on outcome reports was very important in helping them understand the link between the various activities they carried out, the need to report those activities and the link to their sustainability. They reported that the briefing also provided them with an overview of what the outcome report should include. They also understood how outcome reports was a good way of creating public awareness about the challenges faced by their beneficiaries (in this case, English Language teachers).

When asked about the use of the programme evaluation instrument, they reported that the questions made them think ahead about their target outcomes and ways to find evidence of those outcomes being achieved. While they had created survey forms to gather data for past events, they noted that the programme evaluation instrument was useful in helping them formulate specific questions to report outputs and outcomes. This in turn helped them prepare a succinct report to be shared with their stakeholders. 
In addition to feedback from the ELTNPO, the two external experts who were invited to assess the programme evaluation instrument also offered recommendations for improvement. It was recommended that the instrument includes a section requiring NPOs to carry out a needs assessment to understand their capacity for seeing through proposed programmes. It was suggested that such information would be important in helping NPOs think of alternatives when carrying out programmes. It was also recommended that the instrument requires NPOs to identify risk factors and anticipate challenges. While these elements may not be included in outcome reports, adding them to the instrument would likely support NPOs in planning for activities with successful outcomes.

Generally, the use of the programme evaluation instrument by the ELTNPO was effective in two significant ways. First, they were able to think ahead to programme outcomes and develop data collection instruments in preparation for collecting evidence of success. Second, they were able to attempt an outcome report describing tangible outputs and outcomes. The ELTNPO submitted their outcome report to the researchers. Some errors were evident in the outcome report; however, it should be noted that the report was prepared independently by members of the ELTNPO without any advice from the researchers. Among the more significant errors were in the identification of outputs and outcomes. This suggests that more guidelines and examples need to accompany the instrument to support NPOs in preparing an accurate outcome report.

\section{Discussion}

The initial search for Malaysian NPOs which maintained websites revealed that a large number of these NPOs do not maintain such sites, and this suggests lost opportunities for Malaysian NPOs to engage with stakeholders and legitimise their role in society. Unfortunately, it is evident that many NPOs in Malaysia are operating without adequately tapping into the multimedia resources which are available to them for open communication, an important prerequisite for establishing trust among stakeholders and the public at large. This is despite the fact that NPOs have the potential to enhance stakeholder engagement with the right web content (Twis \& Hoefer, 2020), and that websites play an important role in building stakeholder relationships, and providing a platform for fundraising through public engagement (Ingenhoff \& Koelling, 2009, 2010). On speculating about reasons why NPOs do not tap into multimedia resources, Lee and Blouin (2019) suggest that it is essentially resistance to change because adopting web disclosure practices would mean having to abandon the old ways of doing things.

The examination of NPO websites revealed that on the surface at least, Malaysian NPOs were indeed providing opportunities for dialogic communication with stakeholders. The websites showed evidence of a focus on communication strategies which moved beyond merely informing visitors, to also engaging with them in two-way conversations. However, the survey responses and interviews revealed that preferences for modes of dialogic communication were multifaceted, and the NPOs were leveraging on various platforms for establishing stakeholder networks. At the 
same time, the survey also revealed that the NPOs did not have a strong preference for dialogic communication via social media sites, and this is consistent with Ihm's (2019) finding that more social media activities by NPOs did not necessarily correlate with greater stakeholder engagement.

Further interviews with NPOs revealed that effective engagement with stakeholders depended on the willingness to invest in resources. Clearly, communicating effectively with stakeholders had to involve investments of time and money. While there is an awareness that effective communication serves to legitimise their operations and enhance relations with stakeholders, this does not appear to be high enough on the priority list of NPOs for them to invest their resources. The resistance by Malaysian NPOs to invest in effective communication appears consistent with the observations of Kang and Norton (2004) almost two decades earlier when they concluded that the failure of American NPOs to develop functions of interactivity contributed to inefficiencies in creating a dialogic loop with their stakeholders and the public at large. On the same point, Nageswarakurukkal et al. (2020) assert that funds and time must be allocated for efficient communication if NPOs are to convince potential funders to support their initiatives.

Focusing more specifically on the capacity of Malaysian NPOs to measure and report the outcomes of programmes, the analysis of the websites revealed that none of the NPOs presented stand-alone outcome or impact reports of their past activities. This suggests that Malaysian NPOs do not see the value of such reports although De Villiers et al. (2014) observe that stand-alone reports recognise stakeholder demands for more detailed disclosures which help them make informed decisions. Instead, the NPOs presented their reports of past activities through annual reports and/or newsletter publications which were uploaded on their websites. This is despite the assertion that when activity reports are embedded within other documents such as annual reports, they are less likely to meet the information demands of stakeholders (Bouten et al., 2011).

NPOs are dependent on the support of stakeholders and donors for ensuring that they are able to continue with the various initiatives targeting beneficiaries. Continued financial support is therefore key for the sustainability of NPOs, and this is only possible if trust is established, and if donors are convinced that their financial support translates into impact for the target beneficiaries. While NPOs attempt to provide evidence of their trustworthiness by participating in voluntary regulatory programmes, Tremblay-Boire and Prakash (2017) concluded that this does not appear to be sufficient in influencing individuals to donate. One was of legitimising operations and gaining stakeholder confidence may be through the public sharing of effective outcome or impact reports which can serve to signal responsible use of funds by NPOs. Indeed, the reporting of activities and their social impact supports NPOs in building trust (Gazzola et al., 2019).

The analysis revealed that even when activities were reported, the majority of reports failed to present outcomes and impact. Comprehensive reports contribute to greater transparency and accountability (Bouten et al., 2011) which in turn helps establish stakeholder trust. The fact that no report across the 100 Malaysian NPO website contained all 5 elements prescribed by the CASS Centre for Charity Effectiveness (Robert, 2013) for impact assessment and reporting suggests a 
gap in the reporting practices of Malaysian NPOs which needs to be addressed. It should also be noted that the brevity of the reports analysed in the present study indicates a failure of NPOs to systematically disclose information about their initiatives. This observation is consistent with those by Hyndman and McConville (2018) who analysed the reporting practices of the top $100 \mathrm{UK}$ charities. They reported that the format of the reports varied significantly and few charities offered explanations when presenting outputs and outcomes, or linked their activities to their organisation's mission or goals. A primary reason for this is the lack of knowledge needed for measuring and reporting outcomes. Polonsky et al. (2016) suggest that one way of addressing this lack of expertise as well as limited resources is by having NPOs collaborate within sectors to agree on a set of input, output, outcome and impact variables so that social impact may be measured and reported. This will of course be a challenge given the resistance to change among NPOs.

It should be noted that assessing the outcomes of programmes and activities does not necessarily translate into NPO effectiveness (Herman \& Renz, 2008); however, the reporting of programmes, particularly those which are funded, certainly contributes to establishing stakeholder trust (Gazzola et al., 2019). For this reason, there is a need to support NPOs build their capacity for measuring and reporting programme outcomes. The experience with the ELTNPO certainly indicates the capacity of NPOs for adopting the practice of measuring outputs and outcomes, and presenting them in reports.

\section{Conclusion}

The initial search for NPOs which maintained their own websites revealed that Malaysian NPOs are not leveraging on the potential for effective stakeholder interaction through web disclosure practices. The fact that only $30 \%$ of NPOs registered with CCM possessed their own website is an indication of lost opportunities. In the case of NPOs which maintain their own websites, dialogic communication practices varied in terms of the opportunities provided to stakeholders for engagement. This was despite agreement among NPOs in the survey as well as interviews that stakeholder communication was important for sustainability. The engagement with the ELTNPO and the opportunity to take them through the process of preparing an outcome report through the use of a programme evaluation instrument showed that NPOs possess the capacity for effective reporting of their activities if there is support through sufficient exposure and training in outcome reporting practices.

The findings have managerial implications for NPOs. The sustainability of NPOs is dependent on their ability to provide evidence of their legitimacy as organisations which support segments of society. This evidence also serves to inform stakeholders, funders and the public at large that the activities of NPOs meet their organisational goals. The evidence suggests that while there is a desire to voluntarily disclose information, quality reporting requires specific knowledge and skills which NPOs do not possess. Resources must be allocated for capacity building with regard to measuring and reporting performance systematically. The suggestion offered by Polonsky et al. (2016) to have NPOs collaborate in this 
capacity building initiative would certainly be worth considering especially when NPOs are challenged by financial limitations. By extension, there are also managerial implications for regulatory agencies which govern NPOs. These agencies possess the capacity for setting the tone for greater transparency. For example, regulatory agencies are well positioned to encourage self-regulation of voluntary web disclosure by NPOs. This disclosure should include standardised reporting of outcomes guided by a set of rules and accompanying training programmes, because as AbouAssi and Bies (2018) opine, self-regulation which is motivated by a set of formal rules will see NPOs working towards greater legitimacy and compliance.

The present study was limited is several ways. Only a small number of NPOs participated in the survey and this limits the generalisability of the findings. The testing of the programme evaluation instrument was carried out with only one NPO. Future studies will need to consider the feedback on the use of the instrument so that it can be further refined and tested with more NPOs. Moving forward, the findings suggest that there needs to be better regulation of NPO web-reporting practices to ensure that Malaysian NPOs operate within an ecosystem which demands transparency and good governance. Investing in transparent reporting practices will contribute to the growth of the NPO sector (Gazzola et al., 2019). Therefore, initiatives should be introduced to support NPOs better communicate information to their stakeholders, and the public at large. NPOs need to be equipped with knowledge of the principles of outcome and impact assessment which is essential to help them think ahead to programme outcomes, devise data collection instruments, and then publish reports. Extrinsic motivations in the forms of national awards recognising NPOs for their web disclosure practices may serve to encourage them to improve on their existing practices. It is unfortunate that there are no such motivations in Malaysia at the present time because such awards can also support potential donors make informed decisions about collaborations with NPOs.

Research focusing on the voluntary disclosure practices of NPOs remains limited. Future research needs to focus on the measurement and reporting of performance by NPOs. Addressing the limitations in the present study, researchers may want to examine the capacity building capability of NPOs for measuring and reporting the outcomes and long-term impact of their activities. Future research should involve close engagement with NPOs so that the challenges in capacity building are better understood and addressed. As part of this engagement, researchers should explore the potential for collaboration among NPOs as they work towards building their capacity for measuring and reporting outcomes. There also does not appear to be any investigation on the role of regulatory agencies which are tasked with governing NPOs. Given the potential of these agencies is motivating change in the NPO sector, such an investigation is certainly warranted.

Acknowledgements This work was supported by the Digital Society Research Grant awarded by the Malaysian Communications and Multimedia Commission [grant number 100-TNCPI/PRI 16/6/2 (047/2020). 


\section{References}

AbouAssi, K., \& Bies, A. (2018). Relationships and resources: The isomorphism of nonprofit organizations'(NPO) self-regulation. Public Management Review, 20(11), 1581-1601. https:// doi.org/10.1080/14719037.2017.1400583

Bach-Mortensen, A. M., \& Montgomery, P. (2018). What are the barriers and facilitators for third sector organisations (nonprofits) to evaluate their services? A systematic review. Systematic Reviews, 7(13), 1-15. https://doi.org/10.1186/s13643-018-0681-1

Blouin, M. C., Lee, R. L., \& Erickson, G. S. (2018). The impact of online financial disclosure and donations in nonprofits. Journal of Nonprofit \& Public Sector Marketing, 30(3), 251-266. https://doi.org/10.1080/10495142.2018.1452819

Boateng, A., Akamavi, R. K., \& Ndoro, G. (2016). Measuring performance of non-profit organisations: Evidence from large charities. Business Ethics: A European Review, 25(1), 59-74. https:// doi.org/10.1111/beer. 12108

Bocquet, R., Cotterlaz-Rannard, G., \& Ferrary, M. (2020). How do NPOs get funding? A business model perspective based on the conversion of symbolic capital. Nonprofit and Voluntary Sector Quarterly, 49(6), 1233-1258. https://doi.org/10.1177/2F0899764020925912

Bosetti, L. (2018). Web-based integrated CSR reporting: An empirical analysis. Symphonya: Emerging Issues in Management, 1, 18-38. https://doi.org/10.4468/2018.1.02bosetti

Bouten, L., Everaert, P., Van Liedekerke, L., De Moor, L., \& Christiaens, J. (2011). Corporate social responsibility reporting: A comprehensive picture? Accounting Forum, 35(3), 187-204. https:// doi.org/10.1016/j.accfor.2011.06.007

Burlea A. S. \& Popa I. (2013). Legitimacy Theory. In S.O. Idowu, N. Capaldi, L. Zu, \& A.D. Gupta (Eds.), Encyclopedia of Corporate Social Responsibility (pp. 1579-1584). Springer. https://doi. org/10.1007/978-3-642-28036-8_471

Carvalho, A., Ferreira, M. R., \& Lima, S. (2020). Web disclosure of institutional information in nonprofit organizations: An approach in Portuguese charities. International Review on Public and Nonprofit Marketing, 17, 41-58. https://doi.org/10.1007/s12208-019-00235-1

Connolly, C., Hyndman, N., \& McConville, D. (2013). UK charity accounting: An exercise in widening stakeholder engagement. The British Accounting Review, 45(1), 58-69. https://doi.org/10. 1016/j.bar.2012.12.006

Cook, N. J., Wright, G. D., \& Andersson, K. P. (2017). Local politics of forest governance: Why NGO support can reduce local government responsiveness. World Development, 92, 203-214. https:// doi.org/10.1016/j.worlddev.2016.12.005

Cordery, C. J., Crawford, L., Breen, O. B., \& Morgan, G. G. (2019). International practices, beliefs and values in not-for-profit financial reporting. Accounting Forum, 43(1), 16-41. https://doi.org/ $10.1080 / 01559982.2019 .1589906$

Deegan, C. M. (2019). Legitimacy theory: Despite its enduring popularity and contribution, time is right for a necessary makeover. Accounting, Auditing \& Accountability Journal, 32(8), 23072329. https://doi.org/10.1108/AAAJ-08-2018-3638

De Villiers, C., Rinaldi, L., \& Unerman, C. J. (2014). Integrated reporting: Insights, gaps and an agenda for future research. Accounting, Auditing \& Accountability Journal, 27(7), 1042-1067. https://doi.org/10.1108/AAAJ-06-2014-1736

Doan-Bao, C., Papoutsaki, E., \& Dodson, G. (2019). Catalysing social change in Ho Chi Minh City, Vietnam: Evaluating the LIN model of participatory community development. Community Development Journal, 54(3), 519-540. https://doi.org/10.1093/cdj/bsx058

Freeman, R. E., Phillips, R., \& Sisodia, R. (2020). Tensions in stakeholder theory. Business \& Society, 59(2), 213-231. https://doi.org/10.1177/2F0007650318773750

Gálvez-Rodriguez, M. D. M., Caba-Pérez, C., \& López-Godoy, M. (2014). Facebook: A new communication strategy for nonprofit organisations in Colombia. Public Relations Review, 40(5), 868-870. https://doi.org/10.1016/j.pubrev.2014.10.002

Gandia, J. L. (2011). Internet disclosure by nonprofit organizations: Empirical evidence of nongovernmental organizations for development in Spain. Nonprofit and Voluntary Sector Quarterly, 40(1), 57-78. https://doi.org/10.1177/2F0899764009343782

Gazzola, P., Amelio, S., Papagiannis, F., \& Michaelides, Z. (2019). Sustainability reporting practices and their social impact to NGO funding in Italy. Critical Perspectives on Accounting, 79, 1-12. https://doi.org/10.1016/j.cpa.2019.04.006 
Herman, R. D., \& Renz, D. O. (2008). Advancing nonprofit organizational effectiveness research and theory: Nine theses. Nonprofit Management and Leadership, 18(4), 399-415. https://doi.org/10. $1002 / \mathrm{nml} .195$

Hyndman, N., \& McConville, D. (2018). Making charity effectiveness transparent: Building a stakeholder-focussed framework of reporting. Financial Accountability \& Management, 34(2), 133-147. https://doi.org/10.1111/faam.12148

Ihm, J. (2019). Communicating without nonprofit organizations on nonprofits' social media: Stakeholders' autonomous networks and three types of organizational ties. New Media \& Society, 21(11-12), 2648-2670. https://doi.org/10.1177/2F1461444819854806

Ingenhoff, D., \& Koelling, A. M. (2009). The potential of web sites as a relationship building tool for charitable fundraising NPOs. Public Relations Review, 35(1), 66-73. https://doi.org/10.1016/j.pubrev.2008.09.023

Ingenhoff, D., \& Koelling, A. M. (2010). Web sites as a dialogic tool for charitable fundraising NPOs: A comparative study. International Journal of Strategic Communication, 4(3), 171-188. https://doi. org/10.1080/1553118X.2010.489499

JTC Kensington (n.d.). Malaysia companies limited by guarantee. https://www.kensington-trust.com/ resource-center/resources/malaysia-companies-limited-by-guarantee/

Kang, S., \& Norton, H. E. (2004). Nonprofit organizations' use of the world wide web: Are they sufficiently fulfilling organizational goals? Public Relations Review, 30(3), 279-284. https://doi.org/10. 1016/j.pubrev.2004.04.002

Kolhede, E., \& Gomez-Arias, J. T. (2021). Segmentation of individual donors to charitable organizations. International Review on Public and Nonprofit Marketing, 1-33. https://doi.org/10.1007/ s12208-021-00306-2

Lee, R. L., \& Blouin, M. C. (2019). Factors affecting web disclosure adoption in the nonprofit sector. Journal of Computer Information Systems, 59(4), 363-372. https://doi.org/10.1080/08874417.2017. 1370988

Lee, R. L., \& Joseph, R. C. (2013). An examination of web disclosure and organizational transparency. Computers in Human Behavior, 29(6), 2218-2224. https://doi.org/10.1016/j.chb.2013.05.017

Midin, M., Joseph, C., \& Mohamed, N. (2017). Promoting societal governance: Stakeholders' engagement disclosure on Malaysian local authorities' websites. Journal of Cleaner Production, 142, 1672-1683. https://doi.org/10.1016/j.jclepro.2016.11.122

Nageswarakurukkal, K., Gonçalves, P., \& Moshtari, M. (2020). Improving fundraising efficiency in small and medium sized nonprofit organizations using online solutions. Journal of Nonprofit \& Public Sector Marketing, 32(3), 286-311. https://doi.org/10.1080/10495142.2019.1589627

Nair, R., Arshad, R., \& Muda, R. (2020). Utilising dialogic corporate web communication: The case of reputational risk management at Tabung haji. Media International Australia, 181(1), 120-130. https://doi.org/10.1177/2F1329878X20969467

Polonsky, M. J., Grau, S. L., \& McDonald, S. (2016). Perspectives on social impact measurement and nonprofit organisations. Marketing Intelligence \& Planning, 34(1), 80-98. https://doi.org/10.1108/ MIP-11-2014-0221

Ramos, R. F., Rita, P., \& Moro, S. (2019). From institutional websites to social media and mobile applications: A usability perspective. European Research on Management and Business Economics, 25(3), 138-143. https://doi.org/10.1016/j.iedeen.2019.07.001

Ricciuti, E., \& Calo, F. (2018). Are foundations assessing their impact? Concepts, methods and barriers to social impact assessment in Italian foundations. International Review on Public and Nonprofit Marketing, 15(4), 553-574. https://doi.org/10.1007/s12208-018-0213-7

Robert, N. (2013). Impact assessment, tools for success: Doing the right things and doing them right. UK: Cass Business School Centre for Charity Effectiveness. https://www.bayes.city.ac.uk/_data/ assets/pdf_file/0003/160518/11ImpactAssmt.pdf

Rossi, G., Leardini, C., \& Landi, S. (2020). The more you know, the more you give: Influence of online disclosure on European community foundations' donations. Nonprofit Management and Leadership, 31(1), 81-101. https://doi.org/10.1002/nml.21412

Shah, S. Z. A., Zainon, S., Othman, A. A., \& Sundram, V. P. K. (2016). Web-based disclosure: A comparative study between Malaysian and Singaporean non-profit organisations. Information, 19(9B), 4051-4056.

Tremblay-Boire, J., \& Prakash, A. (2017). Will you trust me?: How individual American donors respond to informational signals regarding local and global humanitarian charities. Voluntas: International 
Journal of Voluntary and Nonprofit Organizations, 28(2), 621-647. https://doi.org/10.1007/ s11266-016-9782-4

Twis, M. K., \& Hoefer, R. (2020). Teaching note-Nonprofit websites and the engagement competency of social work education. Journal of Social Work Education, 56(3), 614-621. https://doi.org/10. 1080/10437797.2019.1656583

Waters, R. D., Burnett, E., Lamm, A., \& Lucas, J. (2009). Engaging stakeholders through social networking: How nonprofit organizations are using Facebook. Public Relations Review, 35(2), 102-106. https://doi.org/10.1016/j.pubrev.2009.01.006

Wirtz, J. G., \& Zimbres, T. M. (2018). A systematic analysis of research applying 'principles of dialogic communication' to organizational websites, blogs, and social media: Implications for theory and practice. Journal of Public Relations Research, 30(1-2), 5-34. https://doi.org/10.1080/1062726X. 2018.1455146

Yang, C., \& Northcott, D. (2018). Unveiling the role of identity accountability in shaping charity outcome measurement practices. The British Accounting Review, 50(2), 214-226. https://doi.org/10. 1016/j.bar.2017.09.010

Yang, C., \& Northcott, D. (2019). How can the public trust charities? The role of performance accountability reporting. Accounting \& Finance, 59(3), 1681-1707. https://doi.org/10.1111/acfi.12475

Publisher's note Springer Nature remains neutral with regard to jurisdictional claims in published maps and institutional affiliations. 